\section{Recall of intraoperative events after general anaesthesia and cardiopulmonary bypass}

Andrew A. Phillips MBChB FCAnaes,

Richard F. McLean MD FRCPC,

J. Hugh Devitt MD MSc FRCPC, Ellen M. Harrington BA
We wished to identify patients able to recall intraoperative events after general anaesthesia involving cardiopulmonary bypass (CPB). A balanced anaesthetic technique consisting of benzodiazepines, low dose fentanyl $\left(15.9 \pm 8.5 \mu \mathrm{g} \cdot \mathrm{kg}^{-1}\right)$ and a volatile agent was employed. Perioperative recall was sought utilizing a structured interview on the fourth or fffth postoperative day. During 20 mo 837 patients underwent CPB. Seven hundred patients (84\%) were able to respond to a structured postoperative interview. A detailed chart review was performed in patients with recall and in 60 randomly selected patients without recall. Eight patients (1.14\%) reported recall of intraoperative events. We were unable to identify any differences between the two groups with respect to narcotic, benzodiazepine dosage or usage of inhalational agents. The incidence of recall in patients undergoing cardiac surgery was less in our group than previously reported. It is, however, higher than the $0.2 \%$ incidence recently reported in patients undergoing non-cardiac surgery. This is probably due to patient characteristics and intraoperative factors which make it difficult to avoid periods of relatively light anaesthesia during cardiac surgery.

L'objectif de ce travail est d'identifier les patients capables de se rappeler des événements survenus pendant la chirurgie sous

Key words

ANAESTHESIA: cardiac, cardiopulmonary bypass; ANAESTHETICS INTRAVENOUS: fentanyl, diazepam; ANAESTHETICS VOLATILE: halothane; COMPLICATIONS: awareness, recall.

From the Department of Anaesthesia, Sunnybrook Health Science Centre, University of Toronto, Toronto, Ontario, Canada.

Presented in part at the Canadian Anaesthetists' Society 49th Annual Meeting in Toronto, June 1992.

Address correspondence to: Dr. Richard F. Maclean, C-818, Department of Anaesthesia, Sunnybrook Health Science Centre, 2075 Bayview Avenue, Toronto, Ontario, M4N 3M5, Canada. Accepted for publication 23rd June, 1993. circulation extracorporelle (CEC). L'anesthésie consiste en des benzodiazépines, du fentanyl à faibles doses (15,9 $\pm 8,5$ $\mu \mathrm{g} \cdot \mathrm{kg}^{-1}$ ), et un agent volatile. On recherche la mémoire évocative périopératoire lors d'une interview au quatrième ou cinquième jour postopératoire. Sur une période de 20 mois, 837 patients ont subi une CEC. De ceux-ci, 700 (84\%) sont capables de répondre à une interview postopératoire. Une révision du dossier d'anesthésie est effectuée chez les patients avec mémoire évocative et chez 60 patients sans mémoire évocative. Huit patients $(1,14 \%)$ se rappellent certains événements périopératoires. Il n'y a pas de différence entre les deux groupes au regard de la posologie opiacée, des benzodiazépines ou de la concentration anesthésique. Lincidence de la mémoire évocative chez nos patients de chirurgie cardiaque est moindre que celle d'études antérieures. Elle est toutefois plus élevée que l'incidence de $0,2 \%$ récemment rapportée chez des patients de chirurgie autre que cardiaque. Selon toute probabilité, cette différence est due aux caractéristiques des malades et à des facteurs peropératoires qui ne permettent pas d'éviter pendant la chirurgie cardiaque des périodes d'anesthésie légère.

Patients experiencing awareness during surgical procedures performed under general anaesthesia may subsequently recall intraoperative events. A recent investigation, employing a structured interview, described two patients with recall in a postoperative review of 1000 adults undergoing non-obstetric, non-cardiac, nonneurosurgical, in-patient procedures. 'This incidence of $0.2 \%$ compares favourably with other large surveys, employing similar structured interviews, reporting incidence of awareness of $0.8-1.2 \%$. $^{2-5}$

When cardiac surgery began at our institution in 1989 we had two patients in the first 100 who complained of recall of intraoperative events. This led us to institute a prospective evaluation of all patients undergoing cardiac surgery, in order to assess the incidence of the problem and determine any obvious causes. Subsequent review of the literature revealed very little information about the incidence of recall in cardiac surgery patients. Gold- 
man's 1986 survey of 30 patients undergoing cardiopulmonary bypass (CPB) reported a $23 \%$ incidence of awareness revealed during hypnosis. ${ }^{6} \mathrm{Kim}$ interviewed 55 patients after bypass and recorded an incidence of awareness of $9 \%{ }^{7}$ Because of the lack of a large series, we report the incidence of recall in over 700 patients anaesthetized for cardiac surgery at our institution.

\section{Methods}

All adult patients undergoing cardiopulmonary bypass for cardiac surgery at our hospital between March 27 1990 and October 311991 were included in the survey.

Patients were premedicated according to the anaesthetist's preference. On arrival in the operating room (OR) routine monitoring for cardiovascular anaesthesia was instituted. Anaesthesia was then induced with diazepam or midazolam (1-10 mg), fentanyl (10 $\left.\mu \mathrm{g} \cdot \mathrm{kg}^{-1}\right)$ and when required, thiopentone sodium $\left(0.2-2.0 \mathrm{mg} \cdot \mathrm{kg}^{-1}\right)$. Muscle relaxation was achieved with a bolus of pancuronium $\left(0.12 \mathrm{mg} \cdot \mathrm{kg}^{-1}\right)$. After tracheal intubation end-tidal $\mathrm{CO}_{2}$ and nasopharyngeal temperatures were continually monitored. Anaesthesia was maintained with a volatile agent, primarily halothane, with additional boluses of diazepam and fentanyl at the discretion of the anaesthetist. The lungs were ventilated with an air-oxygen mixture to a $\mathrm{PaCO}_{2}$ of $35-45 \mathrm{mmHg}$ and a pulse oximeter saturation greater than $97 \%$ at all times. During the time of collecting the data, SHSC was participating in a randomized trial of warm versus cold heart surgery. Bypass temperature for patients enrolled in this study was random. For other patients, the bypass temperature was at the discretion of the surgeon. Approximately 500 of the patients would have been randomized to warm or cold heart surgery.

During bypass isoflurane was entrained and benzodiazepines injected into the bypass circuit to help achieve the desired mean perfusion pressure. Post-bypass a volatile agent was introduced in the presence of adequate cardiovascular stability.

On completion of surgery patients were transferred to the cardiovascular intensive care unit (CVICU). In the early postoperative period pain or anxiety was managed with intravenous boluses of morphine or diazepam. The tracheas were extubated in the ICU when deemed ready. Patients were routinely discharged from the CVICU to the ward on the morning of the second postoperative day.

A post-anaesthetic review was performed on the fourth or fifth postoperative day by a research assistant. Included in this assessment was a structured interview relating to perioperative recall. Patients were asked two questions:

Question 1 "What is the very last thing you remember before going to sleep?" From the reply we identified the site of the last pre-induction recall.

Question 2 "What is the very next thing you remember?" From this reply we deduced the site of the first postinduction recall.

In addition they were asked about any memory of intraoperative events. No specific questions relating to dreams or hallucinations were asked. This form of interview is similar to that reported by other groups. ${ }^{1,2}$ All cardiac anaesthetists were aware of the performance and the reason for the interview. A patient was reported as having intraoperative awareness with subsequent recall if their answer to question $\$ 2$ related to intraoperative experiences with subsequent confirmation of these assumptions on review by an anaesthetist.

Patients were assigned to the recall group if their first post-induction memory related to intraoperative events and to the non-recall group if their first post-induction memory related to events occurring after completion of surgery.

A review of anaesthetic charts allowed us to record the dosages of premedicants, induction agents and drugs employed to maintain anaesthesia. Additional information recorded included patients' age, duration of bypass, length of aortic cross-clamping, nasopharyngeal temperatures throughout the procedure and the administration of fluids and vasopressors.

The records of patients reporting intraoperative recall and of 60 randomly selected patients without recall were further scrutinized to determine the percentage of time volatile agents were entrained in the pre-bypass, bypass and post-bypass periods.

When comparing proportions, Fisher's exact test was applied. Wilcoxon rank sum test was used to compare the percentage of time volatile agents were entrained in the groups with and without intraoperative recall.

A $P$ value of $<0.05$ was considered to be statistically significant. All data are reported as mean $\pm \mathrm{SD}$.

\section{Results}

A total of 837 patients underwent cardiopulmonary bypass from the 16th March 1990 to 31st October 1991. The majority of patients underwent coronary artery bypass surgery (Table I). Seven hundred patients (84\%) completed the postoperative interview, their average age, duration of CPB and aortic cross-clamping are illustrated in Table II. One hundred and thirty-seven patients were not interviewed for a variety of reasons (Table III), primarily due to the absence of a research assistant.

The location of the last preoperative recall was the ward in 387 patients, outside the operating room in 137 
TABLE I Surgical procedures performed during cardiopulmonary bypass

\begin{tabular}{lrr}
\hline & $n$ & $\%$ \\
\hline CABG & 629 & 75 \\
Valvular repair/replacement & 158 & 18 \\
Combined CABG and valvular procedure & 25 & 3 \\
Atrial septal repairs & $\underline{25}$ & 3 \\
Total & 837 & \\
\hline
\end{tabular}

Coronary artery bypass grafting (CABG).

TABLE II Age, length of time on CPB and duration of aortic crossclamping (mean $\pm \mathrm{SD}$ ) for patients interviewed

\begin{tabular}{ll}
\hline & mean $\pm S D$ \\
\hline Age (yr) & $60.2 \pm 13.5$ \\
CPB (min) & $94.3 \pm 42.2$ \\
Ao X (min) & $61.0 \pm 25.6$ \\
\hline
\end{tabular}

Duration of complete and partial cardiopulmonary bypass (CPB), duration of complete aortic cross-clamping (Ao X)

and inside the operating room prior to induction in the remaining 177 . The first post-induction recall was intraoperative in eight patients, resulting in a $1.14 \%$ incidence of recall of intraoperative events. Two patients remembered waking up in the OR after the completion of surgery. Analysis of comments suggesting intraoperative awareness allowed us to surmise the timing of the awareness. These comments and descriptions of discomfort experienced are summarized in Table IV. No relationship between recall of intraoperative events and the lowest recorded nasopharyngeal temperature during $\mathrm{CPB}$ could be demonstrated (Table V).

For the group as a whole, the mean dose of fentanyl was $16.9( \pm 9.1) \mu \mathrm{g} \cdot \mathrm{kg}^{-1}$. Five hundred and thirteen patients received only diazepam intraoperatively, the average dose $( \pm S D)$ in these patients was $0.13 \pm 0.06 \mu \mathrm{g} \cdot \mathrm{kg}^{-1}$. One hundred and four received midazolam only, the average dose was $0.10 \pm 0.05 \mathrm{mg} \cdot \mathrm{kg}^{-1}$. Seventy-two patients received a combination of diazepam and midazolam, the average doses were $0.10 \pm 0.04$ and $0.05 \pm$ $0.03 \mathrm{mg} \cdot \mathrm{kg}^{-1}$ respectively. Two patients received lorazepam and/or diazepam and nine received no benzodiazepines. The mean doses of narcotics and benzodiazepines administered to the patients with recall for induction and maintenance of anaesthesia were similar to those administered to the group as a whole: $16.2 \pm 6.7 \mu \mathrm{g} \cdot \mathrm{kg}^{-1}$ fentanyl and $0.12 \pm 0.07 \mathrm{mg} \cdot \mathrm{kg}^{-1}$ diazepam.

A subsequent detailed review of the charts of the eight patients who reported recall and of 60 randomly selected non-recall patients' charts revealed there was no difference in the percentage of time volatile agents were en-
TABLE III Reasons why patients were not interviewed

\begin{tabular}{|c|c|c|c|}
\hline \multicolumn{4}{|c|}{$n$} \\
\hline \multicolumn{2}{|c|}{ Absence of researcher } & \multicolumn{2}{|l|}{89} \\
\hline \multirow{2}{*}{\multicolumn{2}{|c|}{ Patient died }} & \multicolumn{2}{|l|}{17} \\
\hline & & \multicolumn{2}{|l|}{11} \\
\hline \multicolumn{2}{|c|}{ CVA with communication problem } & \multicolumn{2}{|l|}{6} \\
\hline \multicolumn{2}{|c|}{ Prolonged CVICU stay } & \multicolumn{2}{|l|}{2} \\
\hline \multicolumn{2}{|c|}{ Unaccounted } & \multicolumn{2}{|l|}{3} \\
\hline \multicolumn{2}{|c|}{ Total } & \multicolumn{2}{|l|}{137} \\
\hline \multicolumn{4}{|c|}{$\begin{array}{l}\text { Cerebrovascular accident (CVA), cardiovascular intensive care unit } \\
\text { (CVICU). }\end{array}$} \\
\hline \multicolumn{4}{|c|}{ TABLE IV Comments of aware patients } \\
\hline No. & Comments recorded & & Pain \\
\hline 1 & Remembers being sewn up & & $(-)$ \\
\hline 2 & Probing and digging in ches & & $(-)$ \\
\hline 3 & Wondering when operation & & No \\
\hline 4 & Seeing skin, green and blooc & slant & No \\
\hline 5 & $\begin{array}{l}\text { Screws and drains going in, } \\
\text { wonders if eyes taped }\end{array}$ & & Yes \\
\hline 6 & $\begin{array}{l}\text { Heard saw buzzing and voic } \\
\text { requirement for "another vei }\end{array}$ & & No \\
\hline 7 & $\begin{array}{l}\text { Feeling being ripped apart, } \\
\text { "we will have to take" this a }\end{array}$ & ody say & Yes \\
\hline 8 & Heard surgeon say he "had : & & No \\
\hline
\end{tabular}

TABLE V Lowest nasopharyngeal temperature reconded during CPB and the incidence of recall and non-recall of intraoperative events

\begin{tabular}{|c|c|c|}
\hline Temperature ${ }^{\circ} \mathrm{C}$ ) & Recall & Non-recall \\
\hline$<30$ & 3 & 319 \\
\hline $30-31.9$ & 1 & 161 \\
\hline$>31.9$ & $\underline{4}$ & $\underline{212}$ \\
\hline Totals & 8 & 692 \\
\hline
\end{tabular}

Applying Fisher's exact test $P=$ NS.

trained in the pre-bypass, bypass and post-bypass periods of the operation (Table VI).

\section{Discussion}

We report an incidence of awareness with subsequent recall of intraoperative events of $1.14 \%$ in patients undergoing cardiopulmonary bypass with a low-dose narcotic, balanced anaesthetic technique. Episodes of awareness seemed to occur at any time during the operation. Because cooling is associated with a decreased level of consciousness and lowered metabolic rate, we wondered if patients undergoing normothermic bypass might have a higher incidence of recall. We were unable to demonstrate an effect of temperature on recall. The smaller number of patients with recall precludes drawing any definitive 
TABLE VI The percentage of time (mean $\pm \mathrm{SE}$ ) volatile agents were entrained during intraoperative periods for patients with recall and non-recall of intraoperative events (random sample, $n=60$ )

\begin{tabular}{lll}
\hline & \multicolumn{2}{l}{$\%$ of time with vapours on } \\
\cline { 2 - 3 } Intraoperative & $\begin{array}{l}\text { Recall patients } \\
\text { period }\end{array}$ & $\begin{array}{l}\text { Non-recall patients } \\
n=60\end{array}$ \\
\hline Pre-CPB & $72 \pm 30$ & $72 \pm 26$ \\
CPB & $53 \pm 31$ & $48 \pm 23$ \\
Post-CPB & $26 \pm 38$ & $42 \pm 42$ \\
\hline
\end{tabular}

Prior to commencing cardiopulmonary bypass (pre-CPB), during cardiopulmonary bypass (CPB) and after conclusion of cardiopulmonary bypass (post-CPB)

conclusions on the effect of temperature on recall in these patients. Preliminary power calculations show that to have an $80 \%$ power for detecting a halving of the $2 \%$ incidence found in the warm patients, 2100 patients per group would have to be studied.

The objective of general anaesthesia is to provide a state characterized by unconsciousness, muscular relaxation and the suppression of reflex response to noxious stimuli. ${ }^{9}$ The problem which continues to vex anaesthetists is our limited ability to assess our patients' level of consciousness. With the use of muscle relaxants and balanced anaesthesia, the assessment of depth of anaesthesia is difficult. The four stages of anaesthetic depth, as defined by Snow and modified by Guedel, cannot be readily applied to modern anaesthetic practice. ${ }^{10}$ White conceptualizes general anaesthesia as a continuum from intoxication to analgesia then to amnesia, loss of responsiveness and finally loss of motor response. ${ }^{\text {" It }}$ is reasonable to assume that a patient who is not paralyzed, and is unresponsive to surgical stimuli is anaesthetized. " Unfortunately this is rarely seen in cardiac surgery.

Narcotics are effective analgesics, but do not reliably cause amnesia, nor do they produce muscular relaxation. ${ }^{9,12,13}$ Clinicians utilizing narcotics rely on benzodiazepines and inhalational agents for amnesia. Muscular paralysis prevents motor responses. As a result, our ability to assess the depth of anaesthesia is limited. Autonomic signs, such as sweating, tachycardia and hypertension are unreliable indicators of the adequacy of anaesthesia. 1,2,14 Muscular movement as well is unreliable; patients can obey commands under anaesthesia and have no recollection afterwards of the events. ${ }^{14,15}$ Numerous monitoring techniques, including surface electromyography, skin conductance changes, lower esophageal contractility, EEG, and auditory evoked potentials have been utilized as tools for assessing the depth of anaesthesia. ${ }^{14}$ All have weaknesses and are not ready for clinical application.
Combined with our inability to monitor accurately the depth of anaesthesia, the nature of cardiac surgery makes it difficult to avoid periods of "light" anaesthesia. Skin preparation and draping takes $30-40 \mathrm{~min}$ in our institution. The lack of surgical stimulation during this period limits the amount of benzodiazepine and/or inhalational agent administered. Cardiopulmonary bypass itself results in considerable changes in drug concentrations. ${ }^{16}$ Immediately after bypass, concern over haemodynamic instability may restrict administration of anaesthetics.

Given the problems with monitoring the depth of anaesthesia and the limitations imposed on us by the surgery it is not surprising that there is a measurable incidence of recall in these patients. The incidence that we report following CPB is much lower than in two previously published studies of cardiac surgery patients. ${ }^{6,7}$ A similar interview, initially suggested by Brice, ${ }^{8}$ was employed in Kim's and in our study. Kim reported five patients with recall out of a group of 56 for an incidence of $9 \%$. Patients were interviewed $24-76 \mathrm{hr}$ postoperatively. Goldman employed hypnosis in most of his patients prior to performing a semi-structured interview which included two questions relating to last preoperative recall and first postoperative recall. Seven patients out of 30 were able to recall intraoperative events when interviewed 7-10 days after surgery.

The reduction in the incidence of recall found by our group may be due to a variety of factors. While the anaesthetic techniques used in these previous papers are roughly comparable with ours, neither Kim nor Goldman utilized intraoperative benzodiazepines. Continuous feedback was provided to the anaesthetists involved in the care of our patients, resulting in possible practice modifications. Our interviewing technique and timing, while similar, was not identical to that previously reported. Hypnosis was not utilized, patients were asked directly about the first and last thing they remembered surrounding the procedure. The interviewer, however, would only casually ask about recall between the beginning and end of the procedure. It is possible that patients were a little reluctant to report events and, in particular, dreams for fear that they might be deemed inappropriate.

In conclusion we report an incidence of awareness of intraoperative events with subsequent recall of $1.14 \%$ in our patients. As one would expect with such a low incidence, we were unable to identify any consistent factors causing recall. Given the nature of the surgery and the patient population it is not surprising that our incidence of recall is higher than the $0.2 \%$ recently reported for patients undergoing non-cardiac surgery. ${ }^{\prime}$ It is the general impression of our group that we are using larger doses of benzodiazepines and have also increased the utilization of midazolam in the belief that it is a more potent am- 
nestic. The use of continuous infusions of agents such as propofol may also potentially further reduce the incidence of recall in these patients.

\section{References}

1 Liu WHD, Thorp TAS, Graham SG, Aitkenhead AR. Incidence of awareness with recall during general anaesthesia. Anaesthesia 1991; 46: 435-7.

2 Hutchinson $R$. Awareness during surgery: a study of its incidence. Br J Anaesth 1961; 33: 463-9.

3 Harris TJB, Brice DD, Hetherington RR, Utting $J E$. Dreaming associated with anaesthesia: the influence of morphine premedication and two volatile adjuvants. $\mathrm{Br} \mathbf{J}$ Anaesth 1971; 43: 172-8.

4 McKenna T, Wilton TNP. Awareness during endotracheal intubation. Anaesthesia 1973; 28: 599-602.

5 Wilson SL, Vaughan RW, Stephen CR. Awareness, dreams, and hallucinations associated with general anaesthesia. Anesth Analg 1975; 54: 609-17.

6 Goldman L, Shah MV, Hebden $M W$. Memory of cardiac anaesthesia. Anaesthesia, 1987; 42: 596-603.

$7 \mathrm{Kim} C L$. Awareness during cardiopulmonary bypass. American Association of Nxxx Anaesthetists Journal 1978; 46(4): 373-83.

8 Brice DD, Hetherington RR, Utting JE. A simple study of awareness and dreaming during anaesthesia. $\mathrm{Br} \mathrm{J}$ Anaesth 1970; 42: 535-41.

9 Hug CC Jr. Does opioid "anaesthesia" exist? (Editorial). Anesthesiology 1990; 73: 1-4.

10 Dripps $R D$, Eckenhoff JE, Vandam $L D$. Introduction to Anesthesia: The Principles of Safe Practice. Sth ed. Philadelphia: W.B. Saunders Co. Ltd. 1977.

11 White $D C$. Anaesthesia: a privation of the senses. An historical introduction and some definitions. In: Rosen $\mathbf{M}$, Lunn JN (Eds.). Consciousness, Awareness and Pain in General Anaesthesia. London: Butterworths Inc. 1987.

12 Bailey PL, Wilbrink J, Zwanikken P, Pace NL, Stanley $T H$. Anesthestic induction with fentanyl. Anesth Analg. 1985; 64: 48-53.

13 Mark $J B$, Greenberg $L M$. Intraoperative awareness and hypertensive crisis during high-dose fentanyl-diazepam-oxygen anesthesia. Anesth Analg 1983; 62: 698-700.

14 Ghoneim MM, Block RI. Learning and consciousness during general anesthesia. Anesthesiology 1992; 76: 279-305.

15 Tunstall $M E$. Detecting wakefulness during general anaesthesia for caesarean section. BMJ 1977; 1: 1321.

16 Skacel M, Knout C, Reynolds F, Aps C. Extracorporeal circuit sequestration of fentanyl and alfentanil. $\mathrm{Br} \mathrm{J}$ Anaesth 1986; 58: 947-9. 